\title{
A critical look at spatial scale choices in satellite-based aerosol indirect effect studies
}

\author{
B. S. Grandey and P. Stier \\ Atmospheric, Oceanic and Planetary Physics, University of Oxford, Oxford, UK \\ Received: 24 May 2010 - Published in Atmos. Chem. Phys. Discuss.: 22 June 2010 \\ Revised: 28 October 2010 - Accepted: 29 November 2010 - Published: 3 December 2010
}

\begin{abstract}
Analysing satellite datasets over large regions may introduce spurious relationships between aerosol and cloud properties due to spatial variations in aerosol type, cloud regime and synoptic regime climatologies. Using MODerate resolution Imaging Spectroradiometer data, we calculate relationships between aerosol optical depth $\tau_{\mathrm{a}}$, derived liquid cloud droplet effective number concentration $N_{\mathrm{e}}$ and liquid cloud droplet effective radius $r_{\mathrm{e}}$ at different spatial scales. Generally, positive values of $\frac{d \ln N_{\mathrm{e}}}{\ln \tau_{\mathrm{a}}}$ are found for ocean regions, whilst negative values occur for many land regions. The spatial distribution of $\frac{\mathrm{d} \ln r_{\mathrm{e}}}{\mathrm{d} \ln \tau_{\mathrm{a}}}$ shows approximately the opposite pattern, with generally postive values for land regions and negative values for ocean regions. We find that for region sizes larger than $4^{\circ} \times 4^{\circ}$, spurious spatial variations in retrieved cloud and aerosol properties can introduce widespread significant errors to calculations of $\frac{\mathrm{d} \ln N_{\mathrm{e}}}{\mathrm{d} \ln \tau_{\mathrm{a}}}$ and $\frac{d \ln r_{\mathrm{e}}}{\mathrm{d} \ln \tau_{\mathrm{a}}}$. For regions on the scale of $60^{\circ} \times 60^{\circ}$, these methodological errors may lead to an overestimate in global cloud albedo effect radiative forcing of order $80 \%$ relative to that calculated for regions on the scale of $1^{\circ} \times 1^{\circ}$.
\end{abstract}

\section{Introduction}

In order to accurately forecast future warming trends, it is important to quantify present-day radiative forcing due to aerosols (Andreae et al., 2005; Kiehl, 2007). However, there is a large uncertainty in the present day total anthropogenic radiative forcing, and much of this uncertainty is due to uncertainties in the size of indirect aerosol effects on clouds (Forster et al., 2007; Denman et al., 2007; Lohmann and Feichter, 2005).

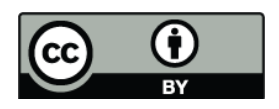

Correspondence to: B. S. Grandey (grandey@atm.ox.ac.uk)
One of these effects is the cloud albedo effect, also known as the first indirect effect. For a cloud of constant liquid water content, increasing the number of cloud condensation nuclei leads to greater competition for available water vapour, resulting in a greater number of smaller droplets. This increases the albedo of the the cloud (Twomey, 1977), resulting in more shortwave radiation being reflected to space. A strong correlation between cloud condensation nuclei concentrations and aerosol optical depth $\tau_{\mathrm{a}}$, the total extinction at a given wavelength due to aerosol in an atmospheric column, has been observed (Andreae, 2009). This suggests that $\tau_{\mathrm{a}}$ can be used as a surrogate for cloud condensation nuclei concentration.

Many observational studies looking of the cloud albedo effect have been published. Quaas et al. (2008) find that higher MODerate resolution Imaging Spectroradiometer (MODIS) $\tau_{\mathrm{a}}$ is generally associated with higher liquid cloud droplet effective number concentration $N_{\mathrm{e}}$ for clouds with a liquid water path $w>20 \mathrm{gm}^{-2}$. Similarly, a surface remote sensing and in situ study has shown that, for stratus clouds off the Californian coast, a positive correlation between $N_{\mathrm{e}}$ and $\tau_{\mathrm{a}}$ exists (McComiskey et al., 2009). They consider different $w$ and spatial resolution constraints. Selecting North Atlantic stratiform clouds, Kaufman et al. (2005) find a negative correlation between MODIS gridded daily $\tau_{\mathrm{a}}$ and liquid cloud droplet effective radius $r_{\mathrm{e}}$, a retrieved estimate of the size of the droplets near the top of liquid water clouds. They perform a multiple regression analysis to investigate the contribution of meteorology to this observed relationship. Using Along Track Scanning Radiometer ATSR-2 data for different regions and seasons, Bulgin et al. (2008) generally observed negative correlations between $\tau_{\mathrm{a}}$ and $r_{\mathrm{e}}$ for clouds below $3 \mathrm{~km}$, although positive correlations were also often observed. Kiran et al. (2009) claim that a decrease in $r_{\mathrm{e}}$ observed during break spells in the Indian monsoon is due to an increase in aerosol transport to the continental tropical convergence zone during the break spells. Using satellite

Published by Copernicus Publications on behalf of the European Geosciences Union. 
data from the POLarization and Directionality of the Earth's Reflectances (POLDER) instrument, Bréon et al. (2002) observe a negative correlation between $r_{\mathrm{e}}$ and aerosol index.

Satellite-observed aerosol and cloud may have different vertical distributions and may not actually mix. Using CALIPSO (Cloud Aerosol Lidar and Infrared Pathfinder Satellite Observation) vertical profile data, Costantino and Bréon (2010) find that a much stronger correlation between PARASOL (Polarization and Anisotropy of Reflectances for Atmospheric Sciences coupled with Observations from a Lidar) $r_{\mathrm{e}}$ and MODIS aerosol index exists for mixed aerosolcloud cases that for non-mixed layers in the Eastern South Atlantic stratocumulus region.

However, observed relationships between aerosol and cloud properties are not necessarily indicative of causal microphysical effects. For example, satellite retrieval errors or meteorological effects, accounted for to differing extents by the aforementioned studies, may contribute towards the observed correlations (Stevens and Feingold, 2009).

Spatially-varying aerosol and cloud climatologies may also often contribute towards observed relationships between aerosol and cloud properties. This may affect the results of many of the aforementioned studies which analyse data on a relatively large regional scale: Bréon et al. (2002) conduct their analysis on a global scale of $360^{\circ} \times 105^{\circ}$; Kaufman et al. (2005) use North Alantic regions of order $100^{\circ} \times 25^{\circ}$; Bulgin et al. (2008) use regions of varying sizes, from $14^{\circ} \times 8^{\circ}$ to $360^{\circ} \times 105^{\circ}$; Quaas et al. (2008) use continental regions of order $100^{\circ} \times 40^{\circ}$. Aerosol type, cloud regime and synoptic regime climatologies may vary over such large-scale regions. If data are analysed for the region as a whole, false correlations may be introduced. For example, a hypothetical ocean region may contain two sub-regions: one characterised by low thin stratocumulus cloud and biomass burning aerosol; the other, more remote, characterised by thicker fragmented cumulus cloud and sea-salt aerosol with a generally lower $\tau_{\mathrm{a}}$. One potential spurious correlation introduced by treating the two sub-regions as one larger region would be the observation that higher $\tau_{\mathrm{a}}$ corresponds to thinner clouds with a larger fractional coverage, relationships which may exist in neither of the sub-regions if they were to be analysed in isolation. Similarly, further spurious relationships between other cloud and aerosol properties may also be introduced by looking at large regions.

In this study, the following two questions are asked: What are sensible choices of spatial scale for aerosol-cloud interaction studies? What effect may spatial scale choices have on global estimates of radiative forcing due to the cloud albedo effect?

A description of the datasets and methodology used in this study is provided in Sect. 2. Results are presented in Sect. 3 and discussed, with reference to these two questions, in Sect. 4.

\section{Method}

\subsection{Data}

The MODIS instruments, onboard the Terra (Kaufman et al., 1998) and Aqua (Parkinson, 2003) satellites, each observe the earth using 36 spectral bands (Barnes et al., 1998). Using these radiances, aerosol and cloud properties are often retrieved. This study uses MODIS Science Team collection 5 daily $1^{\circ} \times 1^{\circ}$ gridded level 3 products retrieved from Terra-MODIS radiances (MOD08_D3) for the ten-year period March 2000-February 2010.

Aerosol optical depth $\tau_{\mathrm{a}}$ values from the joint land and ocean mean aerosol optical depth dataset, retrieved at $550 \mathrm{~nm}$ (Remer et al., 2005), are used here.

For liquid cloud droplet effective radius $r_{\mathrm{e}}$, this study uses values from the quality-assured liquid cloud effective radius dataset. Retrievals of $r_{\mathrm{e}}$ may be highly unreliable. Bréon and Doutriaux-Boucher (2005) find a poor correlation between MODIS and POLDER $r_{\mathrm{e}}$ over land, with a better correlation over ocean, although MODIS $r_{\mathrm{e}}$ is generally higher. Since POLDER is limited to homogeneous cloud fields, their findings apply primarily to homogeneous cloud fields. Marshak et al. (2006) suggest that the MODIS $r_{\mathrm{e}}$ retrieval may be even less reliable for inhomogeneous cloud fields. However, a detailed discussion of $r_{\mathrm{e}}$ uncertainties is outside the scope of the current work (see e.g., Bréon and Doutriaux-Boucher, 2005; Marshak et al., 2006; Vant-Hull et al., 2007). The MODIS $r_{\mathrm{e}}$ product has been used in other studies (e.g., Kaufman et al., 2005; Kiran et al., 2009).

Theoretical considerations predict that, for constant liquid water path $w$, the cloud albedo effect $E_{r}$ with respect to $r_{\mathrm{e}}$ can be written as

$E_{r}=-\left.\frac{\partial \ln r_{\mathrm{e}}}{\partial \ln \tau_{\mathrm{a}}}\right|_{w}$

(Feingold et al., 2001). The requirement of constant $w$ can be removed by instead considering the cloud albedo effect $E_{N}$ with respect to $N_{\mathrm{e}}$ (Feingold et al., 2001; McComiskey et al., 2009):

$$
E_{N}=\frac{\mathrm{d} \ln N_{\mathrm{e}}}{\mathrm{d} \ln \tau_{\mathrm{a}}}=3 E_{r}
$$

Although not a directly-retrieved quantity, liquid cloud droplet effective number concentration, $N_{\mathrm{e}}$, is sometimes estimated using the adiabatic approximation:

$N_{\mathrm{e}}=\gamma \tau_{\mathrm{c}}^{\frac{1}{2}} r_{\mathrm{e}}^{-\frac{5}{2}}$,

where $\tau_{\mathrm{c}}$ is cloud optical depth and $\gamma=1.37 \times 10^{-5} \mathrm{~m}^{-\frac{1}{2}}$ (Brenguier et al., 2000; Quaas et al., 2006). This relationship assumes that liquid water content and liquid cloud droplet radius increase monotonically with height in the cloud, that the true droplet number concentration is constant and that $r_{\mathrm{e}}$ is representative of the true liquid cloud droplet radius at the 


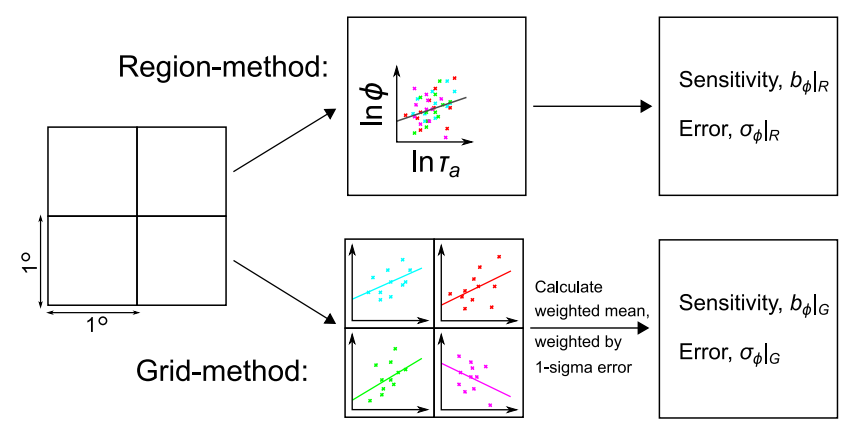

Fig. 1. A schematic illustrating the methods used to calculate sensitivities, applied to a $2^{\circ} \times 2^{\circ}$ region. Each point in the scatter plot represents a $1^{\circ} \times 1^{\circ}$ grid box and day for which both cloud and aerosol data exist. The different colours are used to show data from different grid boxes. For simplicity, only a small number of data points are shown in this schematic.

top of the cloud. If these assumptions are valid, then $N_{\mathrm{e}}$ will be a good proxy for the true droplet number concentration. Further discussion about the validity of Eq. (3) is provided elsewhere (e.g., Kubar et al., 2009). It is worth noting that the conclusions presented in Sect. 4 are not dependent on the validity of Eq. (3), and that the current work also presents results for $r_{\mathrm{e}}$, a directly retrieved cloud property.

$N_{\mathrm{e}}$ is calculated by applying Eq. (3) to the liquid cloud optical thickness and effective radius joint histogram. Thin clouds are more likely to have unreliable $r_{\mathrm{e}}$ measurements, and the retrieval may be less reliable when $r_{\mathrm{e}}<4 \mu \mathrm{m}$ (Nakajima and King, 1990). Following Quaas et al. (2006), clouds with $\tau_{\mathrm{c}}<4$ and $r_{\mathrm{e}}<4 \mu \mathrm{m}$ are excluded when calculating $N_{\mathrm{e}}$. It is worth noting that, assuming vertically homogeneous $r_{\mathrm{e}}$, $w$ is calculated as

$w=\frac{2}{3} \rho_{1} \tau_{\mathrm{c}} r_{\mathrm{e}}$

where $\rho_{1}$ is the density of liquid water (Platnick, 2000). Therefore, removing clouds with $\tau_{\mathrm{c}}<4$ implicitly removes clouds with small $w$ in the calculation of $N_{\mathrm{e}}$. For $r_{\mathrm{e}}=10 \mu \mathrm{m}$, this corresponds to excluding clouds with $w<27 \mathrm{gm}^{-2}$.

Identical sampling has not been applied to the qualityassured $r_{\mathrm{e}}$ used in this study.

The results shown in Sect. 3 have not undergone a singlelayer cloud constraint in the calculation of $N_{\mathrm{e}}$. However, these results are relatively insensitive to the application of such a constraint, as will be shown in Appendix A.

\subsection{Calculation of sensitivities}

Following the method of Quaas et al. (2008), the sensitivity, $b_{\phi}$, of a cloud property, $\phi$, to $\tau_{\mathrm{a}}$ is defined here as

$b_{\phi}=\frac{\mathrm{d} \ln \phi}{\mathrm{d} \ln \tau_{\mathrm{a}}}$.

Of interest to this study is $b_{r_{\mathrm{e}}}$, the sensitivity of $r_{\mathrm{e}}$, (cf. Eq. 1) and $b_{N_{\mathrm{e}}}$, the sensitivity of $N_{\mathrm{e}}$, (cf. Eq. 2).
When calculating sensitivities at $1^{\circ} \times 1^{\circ}$ resolution, Eq. (5) is applied to data for a given season (December-JanuaryFebruary DJF, March-April-May MAM, June-July-August JJA or September-October-November SON) and $1^{\circ} \times 1^{\circ}$ grid box. This methodology can be thought of as calculating the linear regression slope of a scatter plot of $\ln \phi$ vs. $\ln \tau_{\mathrm{a}}$, where each point represents a day for which both aerosol and cloud data exist for this grid box. The one-sigma error of the regression fit is also calculated.

When moving to larger regions, and ultimately the globe, there are two possible ways to extend this methodology, as illustrated in Fig. 1. A single scatter plot for the entire region, where different points represent different combinations of date and $1^{\circ} \times 1^{\circ}$ grid box, could be considered. This is the method used by Quaas et al. $(2008,2009)$ and is very similar to the methods used in the studies discussed in Sect. 1 (Bréon et al., 2002; Kaufman et al., 2005; Bulgin et al., 2008). This is referred to here as the region-method, and its use is indicated by a subscript R, e.g. $\left.b_{N_{\mathrm{e}}}\right|_{\mathrm{R}}$. The region-method samples both temporal and spatial variability.

Alternatively, values of sensitivity for each individual $1^{\circ} \times 1^{\circ}$ grid box could be calculated, before calculating a mean, weighted by the one-sigma error, for the whole region. An error-weighted mean is used in order to reduce the impact of unreliable values with a large error, many of which may be outliers. This second method is referred to as the grid-method, indicated by a subscript G, e.g. $\left.b_{N_{\mathrm{e}}}\right|_{\mathrm{G}}$. The grid-method samples temporal variability only.

In both methods, sensitivities with fewer than five contributing data points are excluded. Further significance testing is also applied, with sensitivities which are insignificant at the two-sigma level being shown as white in Figs. 2, 3, 4 and 5. Both the region-method and the grid-method assume that cloud and aerosol measurements for different grid boxes and days are independent, an assumption which may cause the one-sigma errors calculated in this study to be too small. The validity and effect of this assumption will be discussed further in Appendix A.

As discussed in the introduction, the region-method has the potential to introduce a spurious sensitivity signal due to spurious spatial variations in cloud and aerosol climatologies. This will be demonstrated by randomly shuffling the temporal pairing of cloud and aerosol data within each season and $1^{\circ} \times 1^{\circ}$ grid box, assuming that aerosol and cloud properties for different days are independent. (See Figs. 2 and 4.) The application of this randomisation is indicated by a subscript Rand, e.g. $\left.b_{N_{\mathrm{e}}}\right|_{\mathrm{R} \text {, Rand }}$.

Although the grid-method has the obvious advantage of reducing spatial gradient methodological errors, the error weighting may lead to bias towards regions with a small error in the sensitivity. However, as will be discussed in Appendix A, this does not appear to be a major problem in this study. 


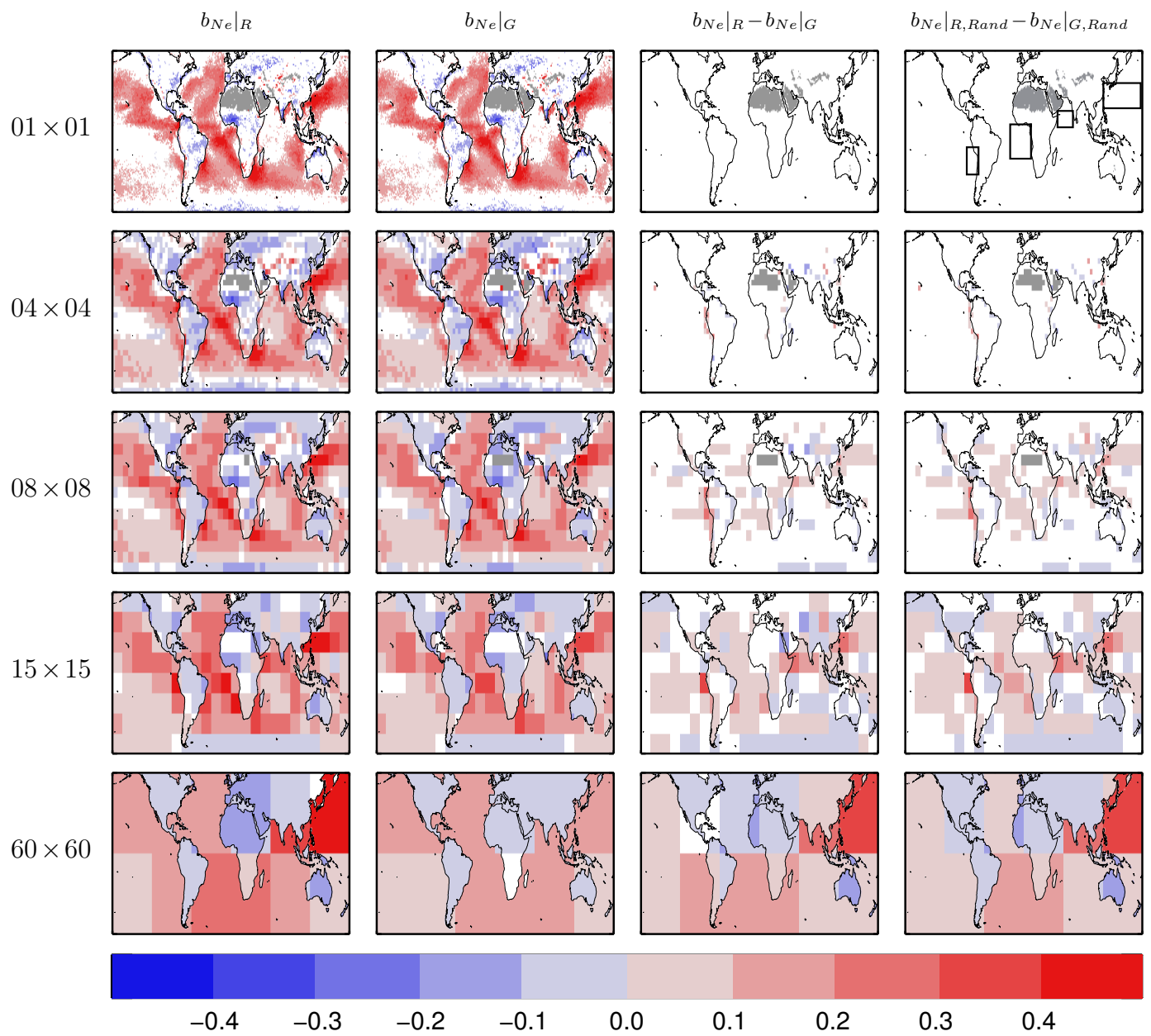

Fig. 2. Annual (all seasons one-sigma error weighted) mean sensitivity of $N_{\mathrm{e}}$ to $\tau_{\mathrm{a}}$ for different region sizes. The first column shows the results for the region-method; the second column is for the grid-method; the third column is the difference between the region-method and grid-method sensitivities; the fourth column is the difference when the data have first been randomised within each season and $1^{\circ} \times 1^{\circ}$ grid box. White regions are where the data are not significantly different from zero at two-sigma confidence, using the error from the sensitivity regression fit. Grey represents missing data. The four rectangles in the top right hand map indicate the regions commented on in Sect. 3.

In order to avoid errors due to retrievals behaving differently between ocean and land, ocean and land regions are analysed separately using a $1^{\circ} \times 1^{\circ}$ land mask.

Near the poles, where surface ice exists and satellite observations are at high solar zenith angles, properties retrieved from satellite data can often be unreliable (e.g., Liu et al., 2009). This problem is mostly avoided by limiting this study to regions between $60^{\circ} \mathrm{N}$ and $60^{\circ} \mathrm{S}$.

A summary of the notation used in this paper is provided for reference in Table 1.

\section{Results}

The first column of Fig. 2 shows the annual mean $\left.b_{N_{\mathrm{e}}}\right|_{\mathrm{R}}$, region-method sensitivity of $N_{\mathrm{e}}$ to $\tau_{\mathrm{a}}$, for different region sizes. The sensitivities are calculated for each season and then an error-weighted annual mean is calculated. The top map, for $1^{\circ} \times 1^{\circ}$ regions, shows positive sensitivities (red) over much of the ocean, indicating that higher $\tau_{\mathrm{a}}$ generally corresponds with higher $N_{\mathrm{e}}$ over these areas, as predicted by the cloud albedo effect conceptual model. In contrast, negative sensitivities (blue) exist for some land areas, indicating that higher $\tau_{\mathrm{a}}$ is associated with lower $N_{\mathrm{e}}$. Much of the map is white, indicating that the calculated $\left.b_{N_{\mathrm{e}}}\right|_{\mathrm{R}}$ values were often not statistically significantly different from zero at the two-sigma confidence level. As the region size increases, the fraction of the globe containing statisically significant $\left.b_{N_{\mathrm{e}}}\right|_{\mathrm{R}}$ increases substantially.

For the grid-method, shown in the second column of Fig. 2, the statistical significance of $\left.b_{N_{\mathrm{e}}}\right|_{\mathrm{G}}$ also improves substantially with increasing region size. The general spatial distribution of grid-method sensitivities is similar to those of the region-method, with $\left.b_{N_{\mathrm{e}}}\right|_{\mathrm{G}}$ being mostly positive over 


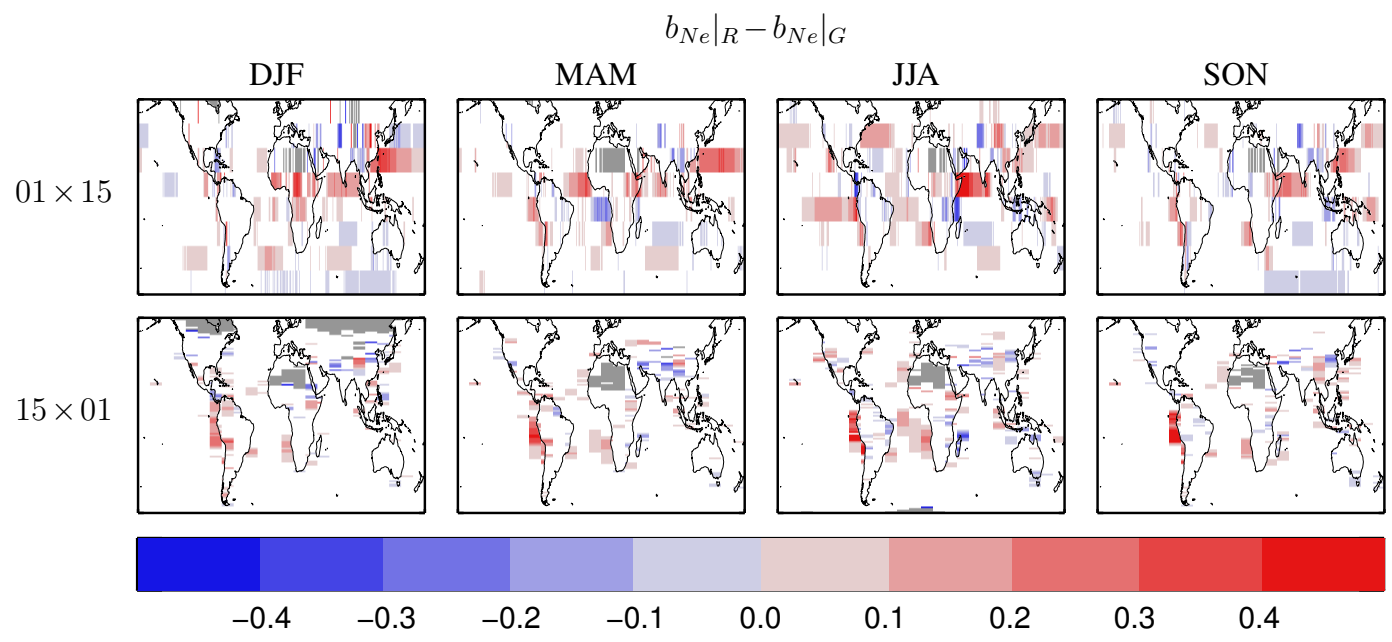

Fig. 3. Difference in sensitivity of $N_{\mathrm{e}}$ to $\tau_{\mathrm{a}}$ between the region-method and grid-method for different seasons and two different region shapes (meridional and zonal). White regions are where the data are not significantly different from zero at two-sigma confidence. Grey represents missing data.

the ocean and negative over land. However, some differences between $\left.b_{N_{\mathrm{e}}}\right|_{\mathrm{R}}$ and $\left.b_{N_{\mathrm{e}}}\right|_{\mathrm{G}}$ are also evident. For example, over the North-West Pacific, near East Asia, the $60^{\circ} \times\left. 60^{\circ} b_{N_{\mathrm{e}}}\right|_{\mathrm{R}}$ is much larger than $\left.b_{N_{\mathrm{e}}}\right|_{\mathrm{G}}$.

The difference between $\left.b_{N_{\mathrm{e}}}\right|_{\mathrm{R}}$ and $\left.b_{N_{\mathrm{e}}}\right|_{\mathrm{G}}$ is shown in the third column of Fig. 2. White shows where the difference is not significantly different from zero at the two-sigma confidence level. The region-method and grid-method only diverge at scales larger than $1^{\circ} \times 1^{\circ}$, so the $1^{\circ} \times\left. 1^{\circ} b_{N_{\mathrm{e}}}\right|_{\mathrm{R}}-\left.b_{N_{\mathrm{e}}}\right|_{\mathrm{G}}$ map shows no difference between the two methods, as expected. At $4^{\circ} \times 4^{\circ}$, differences begin to appear along some of the coasts and land areas, probably due to surface albedo changes causing spatially-varying satellite retrieval errors. At $8^{\circ} \times 8^{\circ}$, many more differences can be seen, including over ocean areas. For $15^{\circ} \times 15^{\circ}$ and $60^{\circ} \times 60^{\circ}$, the presence of significant differences increases substantially.

These results for $\left.b_{N_{\mathrm{e}}}\right|_{\mathrm{R}},\left.b_{N_{\mathrm{e}}}\right|_{\mathrm{G}}$ and $\left.b_{N_{\mathrm{e}}}\right|_{\mathrm{R}}-\left.b_{N_{\mathrm{e}}}\right|_{\mathrm{G}}$ are relatively insensitive to the the application of a single-layer cloud constraint, as will be discussed in Appendix A.

In order to demonstrate that the observed differences occur due to spatial scale changes, the fourth column of Fig. 2 shows the difference between the region-method and the grid-method for data which has been temporally randomised within each $1^{\circ} \times 1^{\circ}$ grid box and season prior to calculationg the annual mean. This randomisation generally causes $\left.b_{N_{\mathrm{e}}}\right|_{\mathrm{G} \text {, Rand }}$ to become insignificantly different from zero, with a few statistically significant departures from zero being the result of noise. The dominant signal in $\left.b_{N_{\mathrm{e}}}\right|_{\mathrm{R}, \text { Rand }}-\left.b_{N_{\mathrm{e}}}\right|_{\mathrm{G}, \text { Rand }}$ is due to spatially-varying changes in $N_{\mathrm{e}}$ and/or $\tau_{\mathrm{a}}$ within regions, either as a result of physical climatologies or surface albedo changes affecting satellite retrievals. The strong similarity between $\left.b_{N_{\mathrm{e}}}\right|_{\mathrm{R}, \text { Rand }}-\left.b_{N_{\mathrm{e}}}\right|_{\mathrm{G}, \mathrm{R} \text { and }}$ and $\left.b_{N_{\mathrm{e}}}\right|_{\mathrm{R}}-\left.b_{N_{\mathrm{e}}}\right|_{\mathrm{G}}$ demonstrates that these sensitivity differences arise as a result of varying climatologies and/or surface albedo within regions.

By looking at different region shapes, it is possible to investigate whether the $\left.b_{N_{\mathrm{e}}}\right|_{\mathrm{R}}-\left.b_{N_{\mathrm{e}}}\right|_{\mathrm{G}}$ differences are predominantly meridional or zonal in nature. Figure 3 shows the difference $\left.b_{N_{\mathrm{e}}}\right|_{\mathrm{R}}-\left.b_{N_{\mathrm{e}}}\right|_{\mathrm{G}}$ for different seasons and two different region definitions: $1^{\circ} \times 15^{\circ}$ (meridional) and $15^{\circ} \times 1^{\circ}$ (zonal). It can be seen that both merdional and zonal changes contribute, with merdional changes being more widespread over the open ocean.

Four ocean areas are worthy of particular mention: the Western North Pacific, to the east of China; the Arabian Sea, between the Horn of Africa and India; the Eastern South Pacific, near the South American coast; and the Eastern South Atlantic, near the African coast. These four regions are indicated on the map at the top right of Fig. 2. Below, each of these four regions is considered briefly.

Parts of the Western North Pacific, to the east of China, show a large difference between $\left.b_{N_{\mathrm{e}}}\right|_{\mathrm{R}}$ and $\left.b_{N_{\mathrm{e}}}\right|_{\mathrm{G}}$ at regionscales of $8^{\circ} \times 8^{\circ}$ and above (Fig. 2), much of which is meridional (Fig. 3). Aerosol properties are known to vary significantly within this region, often exhibiting a gradient in absorptivity and fine-mode fraction with distance from the coast (Choi et al., 2009). A significant part of this variation in aerosol properties is meridional.

The Arabian Sea, between the Horn of Africa and India, also shows a large meridional difference between $\left.b_{N_{\mathrm{e}}}\right|_{\mathrm{R}}$ and $\left.b_{N_{\mathrm{e}}}\right|_{\mathrm{G}}$, particularly during the summer months (Fig. 3). This area often contains airborne dust originating from dust storms, with $\tau_{\mathrm{a}}$ being higher in summer than in winter ( $\mathrm{Li}$ and Ramanathan, 2002). The presence of dust often leads to situations where aerosol and cloud are misidentified (Brennan et al., 2005), leading to errors in retrieved properties. Since 


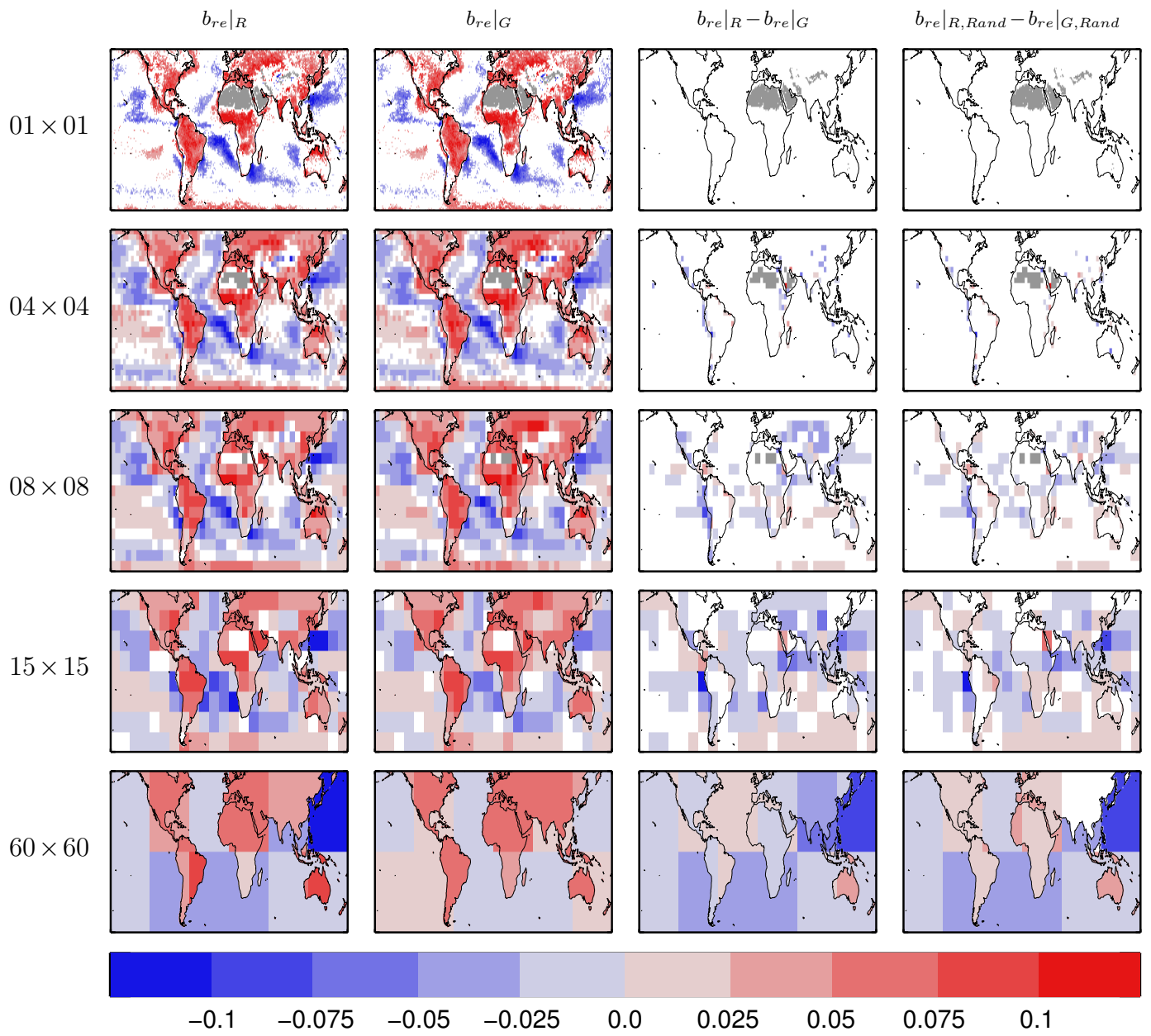

Fig. 4. Same as Fig. 2, but for sensitivity of $r_{\mathrm{e}}$ to $\tau_{\mathrm{a}}$.

there is a strong meridional gradient in $\tau_{\mathrm{a}}$ due to dust over the Arabian Sea (Li and Ramanathan, 2002), this may lead to a meridionally-varying contribution of contamination to retrieved properties.

The results presented here suggest that stratocumulus region indirect effect studies may be particularly susceptible to spatial scale choices. The Eastern South Pacific stratocumulus region, to the west of Peru and Chile, shows persistent differences between $\left.b_{N_{\mathrm{e}}}\right|_{\mathrm{R}}$ and $\left.b_{N_{\mathrm{e}}}\right|_{\mathrm{G}}$ (Figs. 2 and 3). Interestingly, the Eastern South Atlantic stratocumulus region, to the west of Africa, shows a negative meridional difference in MAM but not in other seasons. Aerosol types and cloud properties are known to vary spatially within these regions (e.g., George and Wood, 2010), and variations may have a significant impact on observed aerosol indirect effects (Andrejczuk et al., 2008). These spatial variations must be taken into account when studying stratocumulus regions.

Figures 4 and 5 show $b_{r_{\mathrm{e}}}$, the sensitivity of $r_{\mathrm{e}}$ to $\tau_{\mathrm{a}}$, which exhibits a very similar pattern to Figs. 2 and 3, except for the inverted sign and colour bar range. For the first and second columns of Fig. 4, blue regions show where $b_{r_{\mathrm{e}}}$ is negative, indicating that higher $\tau_{\mathrm{a}}$ generally corresponds with smaller droplets, and red regions show where $b_{r_{\mathrm{e}}}$ is positive, indicating that higher $\tau_{\mathrm{a}}$ corresponds with larger droplets. The aforementioned observations concerning the sensitivity of $N_{\mathrm{e}}$ also apply to the sensitivity of $r_{\mathrm{e}}$. For example, the third column of Fig. 4 shows that statistically significant differences between $\left.b_{r_{\mathrm{e}}}\right|_{\mathrm{G}}$ and $\left.b_{r_{\mathrm{e}}}\right|_{\mathrm{R}}$ emerge as the region size increases. These differences occur mainly along the coast and over land at $4^{\circ} \times 4^{\circ}$, but are found everywhere at $60^{\circ} \times 60^{\circ}$. As before, the fourth column shows that these differences are similar if the data have been randomly shuffled within each $1^{\circ} \times 1^{\circ}$ grid box. The four regions commented on above also show large $\left.b_{r_{\mathrm{e}}}\right|_{\mathrm{R}}-\left.b_{r_{\mathrm{e}}}\right|_{\mathrm{G}}$ differences in Figs. 4 and 5.

Figure 6 shows the relative error introduced to the global average of $b_{N_{\mathrm{e}}}$ through the use of the region-method compared to the grid-method. As expected, this error increases with region size. This error generally acts such that the region-method leads to an overestimate of $b_{N_{\mathrm{e}}}$ compared to the grid-method. For the ocean-land combined and oceanonly sensitivities, this error increases rapidly to $\sim 5-10 \%$ between $4^{\circ} \times 4^{\circ}$ and $8^{\circ} \times 8^{\circ}$. It is at this scale that statistically 


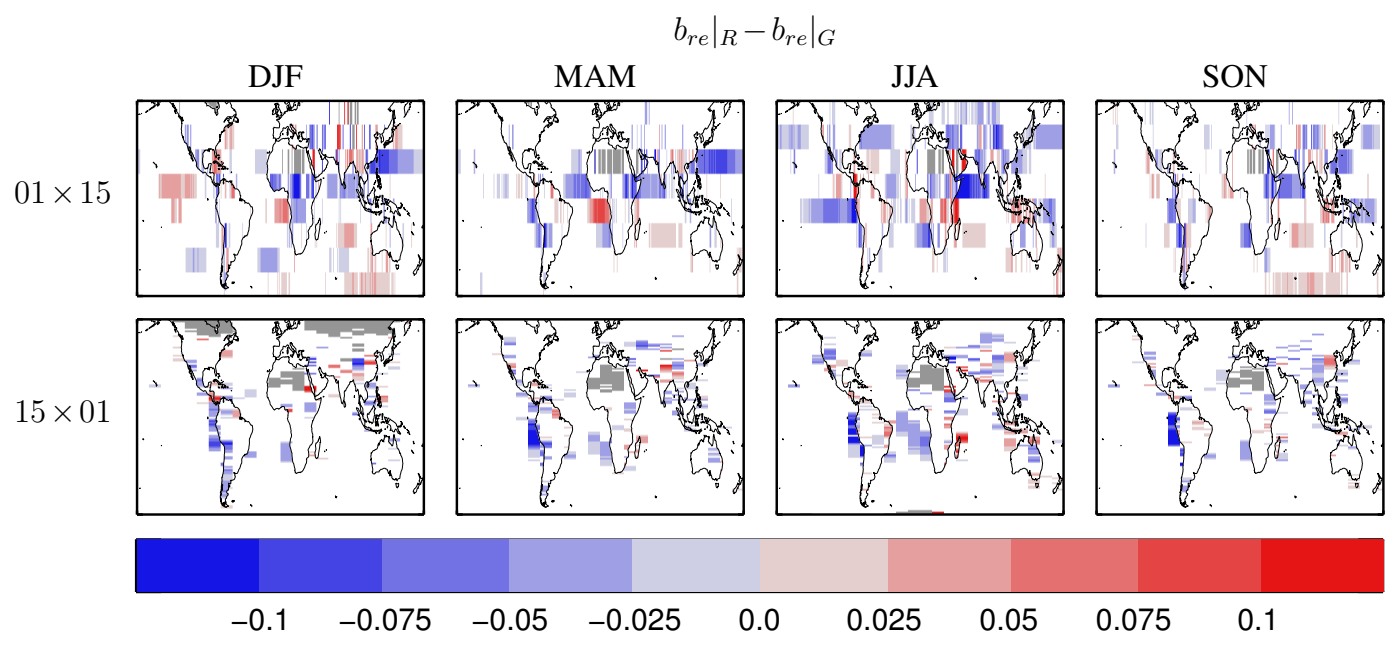

Fig. 5. Same as Fig. 3, but for sensitivity of $r_{\mathrm{e}}$ to $\tau_{\mathrm{a}}$.

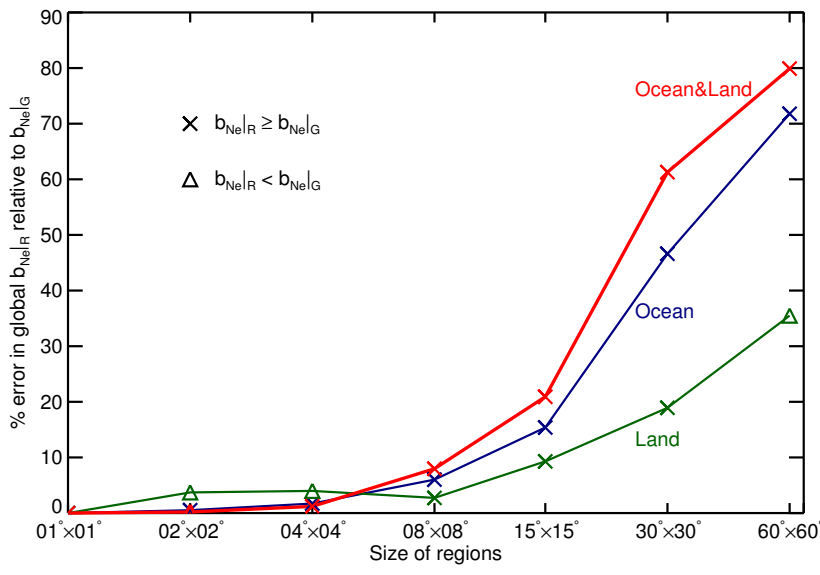

Fig. 6. Absolute percentage error in the globally-averaged sensitivity of $N_{\mathrm{e}}$ to $\tau_{\mathrm{a}}$ due to the region-method compared to the gridmethod. The green data line is for land-only, the blue is for oceanonly and the red is for ocean and land combined. Crosses show where the region-method leads to an overestimate of the sensitivity (i.e. the error is positive), and triangles where the sensitivity is underestimated (the error is negative). As elsewhere in this study, weighting has been applied using the one-sigma error in the sensitivities. Latitudinal area weighting has not been applied.

significant differences begin to become apparent in many individual regions, as shown in Fig. 2 and commented on earlier. Likewise, as can be seen in Fig. 7, for $r_{\mathrm{e}}$ the regionmethod leads to large errors in $b_{r_{\mathrm{e}}}$ at region scales of $8^{\circ} \times 8^{\circ}$ and larger. At $60^{\circ} \times 60^{\circ}$, the ocean-only error in $b_{r_{\mathrm{e}}}$ grows to $\sim 470 \%$.

Errors in sensitivities arising due to the region-method will propogate into associated estimates of cloud albedo effect radiative forcing. Quaas et al. (2008) use large-scale regions, of comparable size to the $60^{\circ} \times 60^{\circ}$ regions used here, to

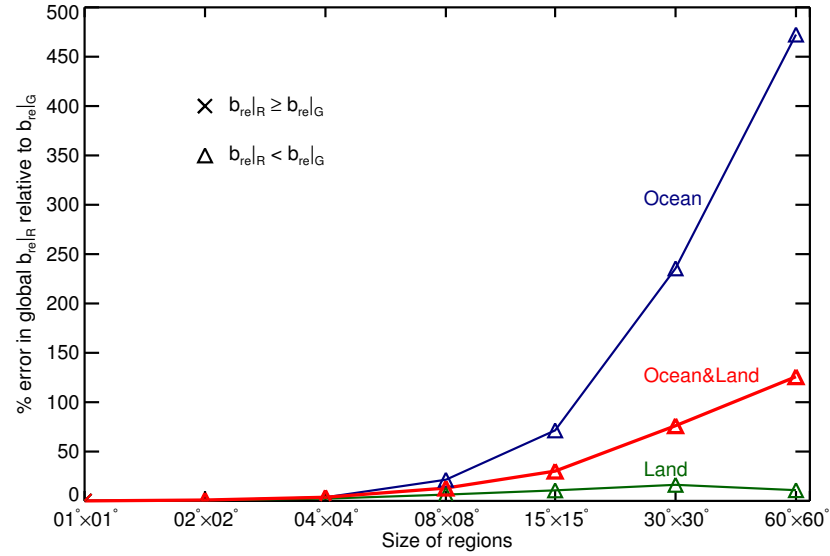

Fig. 7. Same as Fig. 6, but for sensitivity of $r_{\mathrm{e}}$ to $\tau_{\mathrm{a}}$.

estimate radiative forcing. Their cloud albedo effect radiative forcing scales approximately linearly with $b_{N_{\mathrm{e}}}$. As can be seen in Fig. 6, the application of the region-method at $60^{\circ} \times 60^{\circ}$ gives rise to an $80 \%$ error $(70 \%$ error for oceanonly). This would introduce an estimated error of approximately $80 \%$ to the Quaas et al. (2008) cloud albedo effect radiative forcing estimate, modifying their error estimate from $\pm 0.1 \mathrm{~W} \mathrm{~m}^{-2}$ to $\pm 0.2 \mathrm{~W} \mathrm{~m}^{-2}$. Quaas et al. (2008) clearly acknowledge that the uncertainty of their result is likely to be larger than $\pm 0.1 \mathrm{~W} \mathrm{~m}^{-2}$, due to data and methodolical errors being difficult to account for. The current study helps to quantify a methodological error. 
Table 1. A summary of the notation used in this paper.

\begin{tabular}{ll}
\hline Symbol & Meaning \\
\hline$\tau_{\mathrm{a}}$ & aerosol optical depth \\
$r_{\mathrm{e}}$ & liquid cloud droplet effective radius \\
$w$ & cloud liquid water path \\
$\tau_{\mathrm{c}}$ & cloud optical depth \\
$N_{\mathrm{e}}$ & liquid cloud droplet effective number concentration \\
$\phi$ & a general cloud property, either $r_{\mathrm{e}}$ or $N_{\mathrm{e}}$ in this study \\
$\gamma$ & constant in Eq. $(3) ;=1.37 \times 10^{-5} \mathrm{~m}^{-\frac{1}{2}}$ \\
$b_{\phi}$ & the sensitivity, dln $\phi$ \\
$b_{N_{\mathrm{e}}}$, of a general cloud property to $\tau_{\mathrm{a}}$ \\
$\left.b_{N_{\mathrm{e}}}\right|_{\mathrm{R}}$ & sensitivity of $N_{\mathrm{e}}$ to $\tau_{\mathrm{a}}$ \\
$\left.b_{N_{\mathrm{e}}}\right|_{\mathrm{G}}$ & sensitivity of $N_{\mathrm{e}}$ to $\tau_{\mathrm{a}}$, calculated using the region-method \\
$\left.b_{N_{\mathrm{e}}}\right|_{\mathrm{R}, \text { Rand }}$ & sensitivity of $N_{\mathrm{e}}$ to $\tau_{\mathrm{a}}$, calculated using the grid-method \\
$\left.b_{N_{\mathrm{e}}}\right|_{\mathrm{G}, \text { Rand }}$ & sensitivity of $N_{\mathrm{e}}$ to $\tau_{\mathrm{a}}$, calculated using the region-method after data randomisation \\
$b_{r_{\mathrm{e}}}$ & sensitivity of $N_{\mathrm{e}}$ to $\tau_{\mathrm{a}}$, calculated using the grid-method after data randomisation \\
$\left.b_{r_{\mathrm{e}}}\right|_{\mathrm{R}}$ & sensitivity of $r_{\mathrm{e}}$ to $\tau_{\mathrm{a}}$ \\
$\left.b_{r_{\mathrm{e}}}\right|_{\mathrm{G}}$ & sensitivity of $r_{\mathrm{e}}$ to $\tau_{\mathrm{a}}$, calculated using the region-method \\
$\left.b_{r_{\mathrm{e}}}\right|_{\mathrm{R}, \text { Rand }}$ & sensitivity of $r_{\mathrm{e}}$ to $\tau_{\mathrm{a}}$, calculated using the grid-method \\
$\left.b_{r_{\mathrm{e}}}\right|_{\mathrm{G}, \text { Rand }}$ & sensitivity of $r_{\mathrm{e}}$ to $\tau_{\mathrm{a}}$, calculated using the region-method after data randomisation \\
DJF & sensitivity of $r_{\mathrm{e}}$ to $\tau_{\mathrm{a}}$, calculated using the grid-method after data randomisation \\
MAM & Dec-Jan-Feb \\
JJA & Mar-Apr-May \\
SON & Jun-Jul-Aug \\
\hline & Sep-Oct-Nov
\end{tabular}

\section{Conclusions}

This study aimed to address the two questions stated in Sect. 1: what are sensible choices of spatial scale for aerosolcloud interaction studies? What effect may spatial scale choices have on global estimates of radiative forcing due to the cloud albedo effect?

In order to address these questions, the effect of calculating aerosol-cloud relationships in satellite data over a variety of region sizes from $1^{\circ} \times 1^{\circ}$ to $60^{\circ} \times 60^{\circ}$ was investigated. Using MODIS satellite data, sensitivities (Eq. 5) of derived $N_{\mathrm{e}}$ to $\tau_{\mathrm{a}}$ and retrieved $r_{\mathrm{e}}$ to $\tau_{\mathrm{a}}$ were calculated for these different spatial scale choices.

Generally, positive values of the sensitivity of derived $N_{\mathrm{e}}$ to $\tau_{\mathrm{a}}$ are found for ocean regions, whilst negative values occur for many land regions. The spatial distribution of the sensitivity of retrieved $r_{\mathrm{e}}$ to $\tau_{\mathrm{a}}$ shows the opposite pattern, with generally positive values for land regions and negative values for ocean regions.

It was found that analysing datasets over large regional scales has the potential to introduce significant errors to aerosol indirect effect studies. For regions of size $4^{\circ} \times 4^{\circ}$, spatial scale errors are generally small $(\ll 10 \%$ for the sensitivity of both $N_{\mathrm{e}}$ and $r_{\mathrm{e}}$ ) but often become much more significant at region sizes of $8^{\circ} \times 8^{\circ}$ and larger. At larger region scales, these errors can become much larger. For example, for regions of size $60^{\circ} \times 60^{\circ}$ the global ocean-only error in the sensitivity of $r_{\mathrm{e}}$ is $\sim 470 \%$. The existence of these spa- tial scale errors appears to be robust to the application of a single-layer cloud constraint and also does not appear to be the result of a sampling bias due to error weighting.

In light of these findings, it seems sensible to recommend $4^{\circ} \times 4^{\circ}$ as the largest size of individual regions that should be used for analysis in aerosol indirect effect studies. Caution should be applied if looking at larger regions. If data exist at a higher gridded resolution (e.g. $1^{\circ} \times 1^{\circ}$ ), the possibility of analysing data at this higher resolution should be seriously considered. Results of calculations done at these small spatial scales can then be averaged over larger regions, allowing overall results to be calculated for large regions and the globe. Of course, it may not always be possible to conduct analyses at the small spatial scales recommended here. Dataset limitations may prohibit this, particularly when extra temporal and meteorological constraints reduce dataset size. Potential spatial scale methodological errors should be considered alongside other considerations.

The results presented in Sect. 3 suggest that stratocumulus regions are particularly susceptible to such methodological errors, and particular care must be taken when studying such regions.

For large regions, spatial scale errors may lead to large errors in estimates of global cloud albedo effect radiative forcing. For regions on the scale of $60^{\circ} \times 60^{\circ}$, this study suggests that this methodological error in radiative forcing is of order $80 \%$. The corresponding ocean-only error in radiative forcing is of order $70 \%$. 
This study focuses on the cloud properties, $N_{\mathrm{e}}$ and $r_{\mathrm{e}}$, which are often of interest in cloud albedo effect studies. The methodological errors explored here highlight a potential source of inaccuracy in some of the cloud albedo effect studies mentioned in Sect. 1 (e.g., Bréon et al., 2002; Kaufman et al., 2005; Bulgin et al., 2008; Quaas et al., 2008). Although other cloud properties are not investigated here, it is likely that similar methodological errors may also affect the findings of studies which use large regions to investigate other aerosol indirect effects (e.g., Koren et al., 2005, 2008; Jones et al., 2009). However, the additional cloud type and meteorological constraints applied in several of these studies may make their results less susceptible to the spatial gradient effects discussed here.

Finally, it is worth noting that even small regions experience changes in cloud regime and aerosol conditions, often as a result of meteorology. This may lead to spurious correlations unaccounted for in this study, and is the basis for future work. One possible further approach would be to investigate the contribution of temporal climatological gradients, analogous to the spatial gradients discussed here. However, although seasonal temporal scale choices should be considered, this would not fully account for meteorological effects. The development of more advanced methods to investigate the contribution of meteorology to observed aerosol-cloud relationships would be highly beneficial.

\section{Appendix A}

\section{Discussion of methodological choices}

When calculating the sensitivities shown in Sect. 3, no single-layer-only cloud constraint was applied, a decision which has the potential to impact the results. The decision to use one-sigma error weighting also has the potential to impact the results through the introduction of a sampling bias. When calculating errors, it was assumed that data for different grid boxes and days are independent. The discussion below briefly discusses the implications of these three decisions, focusing on the $N_{\mathrm{e}}$ sensitivities. It is found that the $N_{\mathrm{e}}$ results are relatively robust with respect to these decisions. It is likely that the same would apply to the $r_{\mathrm{e}}$ results.

\section{A1 The effect of not applying a single-layer cloud constraint}

The $N_{\mathrm{e}}$ and $r_{\mathrm{e}}$ results presented in Sect. 3 and the first row of Fig. A1 are for all liquid clouds (i.e. no single-layer cloud constraint has been applied). For comparison, the annual mean $60^{\circ} \times 60^{\circ} N_{\mathrm{e}}$ sensitivities shown in the second row of Fig. A1 use $N_{\mathrm{e}}$ values calculated from the single-layer cloud histogram. As can be seen by comparison of the first and second rows, although some of the details may change, the ap- plication of a single-layer constraint does not appear to have a significant effect here. In particular, the general global picture of $\left.b_{N_{\mathrm{e}}}\right|_{\mathrm{R}}-\left.b_{N_{\mathrm{e}}}\right|_{\mathrm{G}}$ changes little.

\section{A2 The effect of one-sigma error weighting}

Weighting by the one-sigma error when calculating $\left.b_{N_{\mathrm{e}}}\right|_{\mathrm{G}}$ for regions larger than $1^{\circ} \times 1^{\circ}$ and multi-season means of both $\left.b_{N_{\mathrm{e}}}\right|_{\mathrm{G}}$ and $\left.b_{N_{\mathrm{e}}}\right|_{\mathrm{R}}$ has the potential to introduce a bias towards regions and seasons with a low one-sigma error. In order to demonstrate that this potential problem does not appear to be the major contributor to the region and grid method differences discussed in this paper, the third row of Fig. A1 shows annual mean $60^{\circ} \times 60^{\circ} N_{\mathrm{e}}$ sensitivities calculated with no error weighting. As can be seen by comparison of the first and third rows of Fig. A1, the overall global picture remains similar.

\section{A3 The assumption of data independence}

When calculating errors for the insignifance masks, it was assumed that data for different grid boxes and days are independent. This assumption may not be valid, because cloud and aerosol properties may often have significant autocorrelations at spatial scales greater than one degree and temporal scales longer than one day (e.g. Anderson et al., 2003). Due to this assumption of independence, the one-sigma errors calculated in this study may be too small.

In order to test the robustness of some of the results presented in Sect. 3 to the possibility of data dependence, let us consider a situation where only $\frac{1}{25}$ of our data may be truly independent. This will result in a scaling of the independence-assumed errors by a factor of $\sqrt{25}=5$. When testing for insignificance, a two-sigma mask on the new errors would therefore correspond to a ten-sigma mask on the old independence-assumed errors, as shown in the final row of Fig. A1. Comparison of the final rows of Figs. 2 and A1 shows that the possibility of data dependence may increase the number of regions where $\left.b_{N_{\mathrm{e}}}\right|_{\mathrm{R}}-\left.b_{N_{\mathrm{e}}}\right|_{\mathrm{G}}$ is insignificant. However, $\left.b_{N_{\mathrm{e}}}\right|_{\mathrm{R}}-\left.b_{N_{\mathrm{e}}}\right|_{\mathrm{G}}$ remains significant for the majority of regions.

Acknowledgements. MODIS data were obtained from the Level 1 and Atmosphere Archive and Distribution System (LAADS). This work was supported by a UK Natural Environment Research Council (NERC) DPhil studentship and also NERC NE/G006148/1. The authors would like to thank Johannes Quaas, Till Wagner, Rosalind West, Andy Sayer, Gareth Thomas, Don Grainger, Myles Allen and two anonymous reviewers for helpful discussions and comments on the manuscript.

Edited by: T. Garrett 


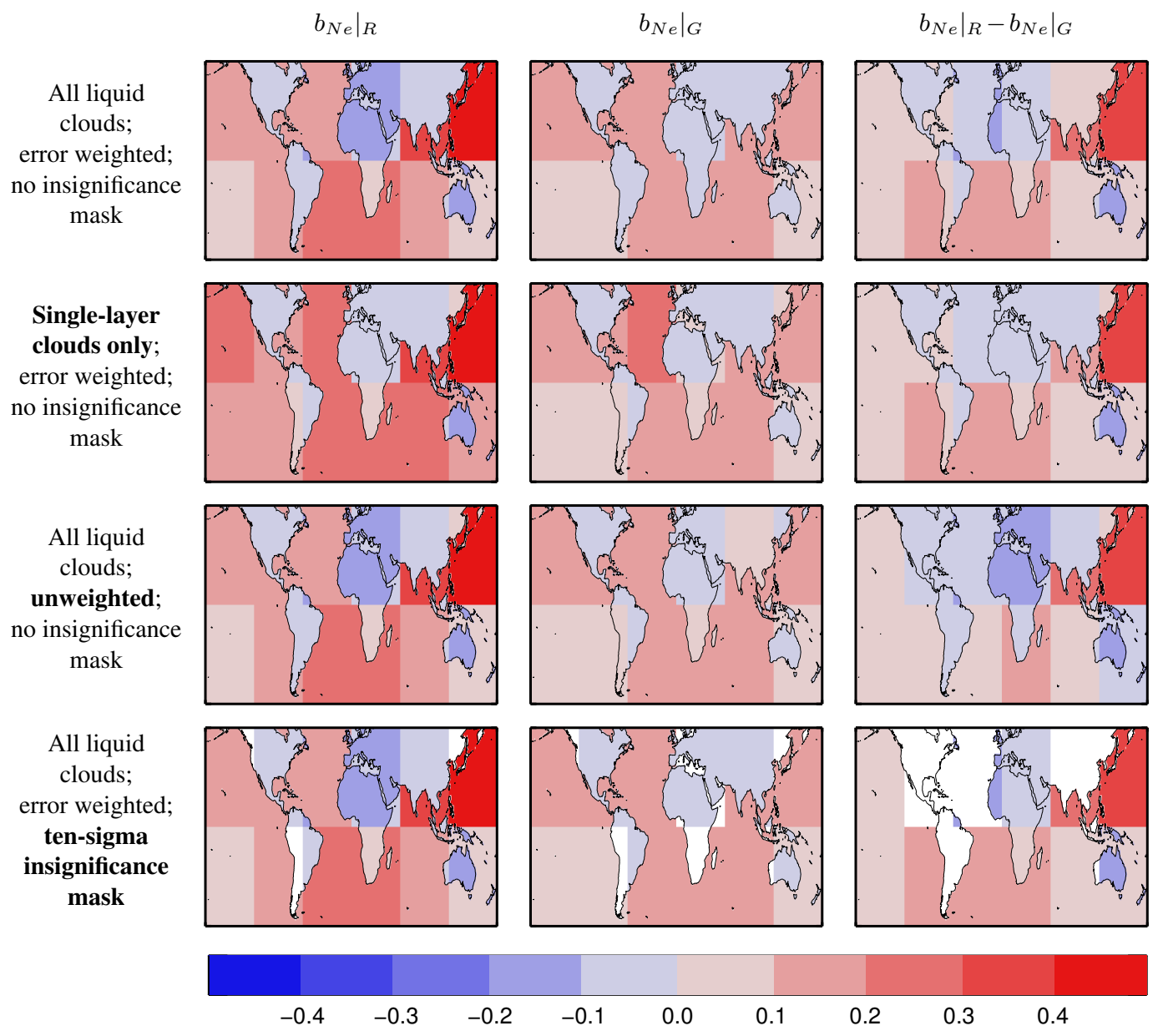

Fig. A1. Annual mean sensitivity of single-layer-only $N_{\mathrm{e}}$ to $\tau_{\mathrm{a}}$ for regions of size $60^{\circ} \times 60^{\circ}$. The first column shows the results for the region-method; the second column is for the grid-method; the third column is the difference between the region-method and grid-method sensitivities. The first row shows the results for when the single-layer cloud constraint is not applied to the calculation of $N_{\mathrm{e}}$ and for when one-sigma error weighting is used to combine sensitivities for $1^{\circ} \times 1^{\circ}$ grid boxes to $60^{\circ} \times 60^{\circ}$ regions (grid-method) and sensitivities for individual seasons to annual means (both methods), like the $b_{N_{\mathrm{e}}}$ results shown in Fig. 2; the second row shows the results for when the single-layer cloud contraint is applied to the calculation of $N_{\mathrm{e}}$; the third row shows the results for when error weighting is not used; the fourth row shows the results for when a ten-sigma insignifcance mask is applied. No insignificance mask has been applied to the first three rows.

\section{References}

Anderson, T. L., Charlson, R. J., Winker, D. M., Ogren, J. A., and Holmén, K.: Mesoscale variations of tropospheric aerosols, J. Atmos. Sci., 60, 119-136, 2003.

Andreae, M. O.: Correlation between cloud condensation nuclei concentration and aerosol optical thickness in remote and polluted regions, Atmos. Chem. Phys., 9, 543-556, doi:10.5194/acp-9-543-2009, 2009.

Andreae, M. O., Jones, C. D., and Cox, P. M.: Strong present-day aerosol cooling implies a hot future, Nature, 435, 1187-1190, doi:10.1038/nature03671, 2005.

Andrejczuk, M., Reisner, J. M., Henson, B., Dubey, M. K., and Jeffery, C. A.: The potential impacts of pollution on a nondrizzling stratus deck: does aerosol number matter more than type?, J. Geophys. Res., 113, D19204, doi:10.1029/2007JD009445, 2008.
Barnes, W. L., Pagano, T. S., and Salomonson, V. V.: Prelaunch characteristics of the moderate resolution imaging spectroradiometer (MODIS) on EOS-AMI, IEEE T. Geosci. Remote, 36, 1088-1100, 1998.

Brenguier, J.-L., Pawlowska, H., Schüller, L., Preusker, R., Fischer, J., and Fouquart, Y.: Radiative properties of boundary layer clouds: droplet effective radius versus number concentration, J. Atmos. Sci., 57, 803-821, 2000.

Brennan, J. I., Kaufman, Y. J., Koren, I., and Li, R. R.: Aerosol-cloud interaction-misclassification of MODIS clouds in heavy aerosol, IEEE T. Geosci. Remote, 43, 911-915, doi:10.1109/TGRS.2005.844662, 2005.

Bréon, F.-M. and Doutriaux-Boucher, M.: A comparison of cloud droplet radii measured from space, IEEE T. Geosci. Remote, 43, 1796-1805, doi:10.1109/TGRS.2005.852838, 2005.

Bréon, F.-M., Tanré, D., and Generoso, S.: Aerosol effect on cloud 
droplet size monitored from satellite, Science, 295, 834-838, doi:10.1126/science.1066434, 2002.

Bulgin, C. E., Palmer, P. I., Thomas, G. E., Arnold, C. P. G., Campmany, E., Carboni, E., Grainger, R. G., Poulsen, C., Siddans, R., and Lawrence, B. N.: Regional and seasonal variations of the Twomey indirect effect as observed by the ATSR-2 satellite instrument, Geophys. Res. Lett., 35, L02811, doi:10.1029/2007GL031394, 2008.

Choi, Y.-S., Ho, C.-H., Oh, H.-R., Park, R. J., and Song, C.-G.: Estimating bulk optical properties of aerosols over the Western North Pacific by using MODIS and CERES measurements, Atmos. Environ., 43, 5654-5660, doi:10.1016/j.atmosenv.2009.07.036, 2009.

Costantino, L. and Bréon, F. M.: Analysis of aerosol-cloud interaction from multi-sensor satellite observations, Geophys. Res. Lett., 37, L11801, doi:10.1029/2009GL041828, 2010.

Denman, K. L., Brasseur, G., Chidthaisong, A., Ciais, P., Cox, P. M., Dickinson, R. E., Hauglustaine, D., Heinze, C. Holland, E., Jacob, D., Lohmann, U., Ramachandran, S., da Silva Dias, P. L., Wofsy, S. C., and Zhang, X.: Couplings between changes in the climate system and biogeochemistry, in: Climate Change 2007: The Physical Science Basis. Contribution of Working Group 1 to the Fourth Assessment Report of the Intergovernmental Panel on Climate Change, Cambridge University Press, 2007.

Feingold, G., Remer, L. A., Ramaprasad, J., and Kaufman, Y. J.: Analysis of smoke impact on clouds in Brazilian biomass burning regions: an extension of Twomey's approach, J. Geophys. Res., 106, 22907-22922, doi:10.1029/2001JD000732, 2001.

Forster, P., Ramaswamy, V., Artaxo, P., Berntsen, T., Betts, R., Fahey, D. W., Haywood, J., Lean, J., Lowe, D. C., Myhre, G., Nganga, J., Prinn, R., Raga, G., Schultz, M., and Van Dorland, R.: Changes in atmospheric constituents and in radiative forcing, in: Climate Change 2007: The Physical Science Basis. Contribution of Working Group 1 to the Fourth Assessment Report of the Intergovernmental Panel on Climate Change, Cambridge University Press, 2007.

George, R. C. and Wood, R.: Subseasonal variability of low cloud radiative properties over the southeast Pacific Ocean, Atmos. Chem. Phys., 10, 4047-4063, doi:10.5194/acp-10-4047-2010, 2010.

Jones, T. A., Christopher, S. A., and Quaas, J.: A six year satellitebased assessment of the regional variations in aerosol indirect effects, Atmos. Chem. Phys., 9, 4091-4114, doi:10.5194/acp-94091-2009, 2009.

Kaufman, Y. J., Herring, D. D., Ranson, K. J., and Collatz, J. G.: Earth observing system AMI mission to earth, IEEE T. Geosci. Remote, 36, 1045-1055, 1998.

Kaufman, Y. J., Koren, I., Remer, L. A., Rosenfeld, D., and Rudich, Y.: The effect of smoke, dust, and pollution aerosol on shallow cloud development over the Atlantic Ocean, P. Natl. Acad. Sci. USA, 102, 11207-11212, doi:10.1073/pnas.0505191102, 2005.

Kiehl, J. T.: Twentieth century climate model response and climate sensitivity, Geophys. Res. Lett., 34, L22710, doi:10.1029/2007GL031383, 2007.

Kiran, V. R., Rajeevan, M., Rao, S. V. B., and Rao, N. P.: Analysis of variations of cloud and aerosol properties associated with active and break spells of Indian summer mon- soon using MODIS data, Geophys. Res. Lett., 36, L09706, doi:10.1029/2008GL037135, 2009.

Koren, I., Kaufman, Y. J., Rosenfeld, D., Remer, L. A., and Rudich, Y.: Aerosol invigoration and restructuring of the Atlantic convective clouds, Geophys. Res. Lett., 32, L14828, doi:10.1029/2005GL023187, 2005.

Koren, I., Martins, J. V., Remer, L. A., and Afargan, H.: Smoke invigorations versus inhibition of clouds over the Amazon, Science, 321, 946-949, doi:10.1126/science.1159185, 2008.

Kubar, T. L., Hartmann, D. L., and Wood, R.: Understanding the importance of microphysics and macrophysics for warm rain in marine low clouds. Part I: Satellite observations, J. Atmos. Sci., 66, 2953-2972, doi:10.1175/2009JAS3071.1, 2009.

Li, F. and Ramanathan, V.: Winter to summer monsoon variation of aerosol optical depth over the tropical Indian Ocean, J. Geophys. Res., 107(D16), 4284, doi:10.1029/2001JD000949, 2002.

Liu, J. C., Schaaf, C., Strahler, A., Jiao, Z. T., Shuai, Y. M., Zhang, Q. L., Roman, M., Augustine, J. A., and Dutton, E. G.: Validation of Moderate Resolution Imaging Spectroradiometer (MODIS) albedo retrieval algorithm: dependence of albedo on solar zenith angle, J. Geophys. Res., 114, D01106, doi:10.1029/2008JD009969, 2009.

Lohmann, U. and Feichter, J.: Global indirect aerosol effects: a review, Atmos. Chem. Phys., 5, 715-737, doi:10.5194/acp-5-7152005, 2005.

Marshak, A., Platnick, S., Várnai, T., Wen, G., and Cahalan, R. F.: Impact of three-dimensional radiative effects on satellite retrievals of cloud droplet sizes, J. Geophys. Res., 111, D09207, doi:10.1029/2005JD006686, 2006.

McComiskey, A., Feingold, G., Frisch, A. S., Turner, D. D., Miller, M. A., Chiu, J. C., Min, Q., and Ogren, J. A.: An assessment of aerosol-cloud interactions in marine stratus clouds based on surface remote sensing, J. Geophys. Res., 114, D09203, doi:10.1029/2008JD011006, 2009.

Nakajima, T. and King, M. D.: Determination of the optical thickness and effective particle radius of clouds from reflected solar radiation measurements. Part I: Theory, J. Atmos. Sci., 47, 1878 1893, 1990.

Parkinson, C. L.: Aqua: an earth-observing satellite mission to examin water and other climate variables, IEEE T. Geosci. Remote, 41, 173-183, doi:10.1109/TGRS.2002.808319, 2003.

Platnick, S.: Vertical photon transport in cloud remote sensing problems, J. Geophys. Res., 105, 22919-22935, doi:10.1029/2000JD900333, 2000.

Quaas, J., Boucher, O., and Lohmann, U.: Constraining the total aerosol indirect effect in the LMDZ and ECHAM4 GCMs using MODIS satellite data, Atmos. Chem. Phys., 6, 947-955, doi:10.5194/acp-6-947-2006, 2006.

Quaas, J., Boucher, O., Bellouin, N., and Kinne, S.: Satellite-based estimate of the direct and indirect aerosol climate forcing, J. Geophys. Res., 113, D05204, doi:10.1029/2007JD008962, 2008.

Quaas, J., Ming, Y., Menon, S., Takemura, T., Wang, M., Penner, J. E., Gettelman, A., Lohmann, U., Bellouin, N., Boucher, O., Sayer, A. M., Thomas, G. E., McComiskey, A., Feingold, G., Hoose, C., Kristjánsson, J. E., Liu, X., Balkanski, Y., Donner, L. J., Ginoux, P. A., Stier, P., Grandey, B., Feichter, J., Sednev, I., Bauer, S. E., Koch, D., Grainger, R. G., Kirkevåg, A., Iversen, T., Seland, Ø., Easter, R., Ghan, S. J., Rasch, P. J., Morrison, H., Lamarque, J.-F., Iacono, M. J., Kinne, S., and Schulz, M.: 
Aerosol indirect effects - general circulation model intercomparison and evaluation with satellite data, Atmos. Chem. Phys., 9, 8697-8717, doi:10.5194/acp-9-8697-2009, 2009.

Remer, L. A., Kaufman, Y. J., Tanré, D., Mattoo, S., Chu, D. A., Martins, J. V., Li, R.-R., Ichoku, C., Levy, R. C., Kleidman, R. G., Eck, T. F., Vermote, E., and Holben, B. N.: The MODIS aerosol algorithm, products, and validation, J. Atmos. Sci., 62, 947-973, doi:10.1175/JAS3385.1, 2005.
Stevens, B. and Feingold, G.: Untangling aerosol effects on clouds and precipitation in a buffered system, Nature, 461, 607-613, doi:10.1038/nature08281, 2009.

Twomey, S.: The influence of pollution on the shortwave albedo of clouds, J. Atmos. Sci., 34, 1149-1152, 1977.

Vant-Hull, B., Marshak, A., Remer, L. A., and Li, Z. Q.: The effects of scattering angle and cumulus cloud geometry on satellite retrievals of cloud droplet effective radius, IEEE T. Geosci. Remote, 45, 1039-1045, doi:10.1109/TGRS.2006.890416, 2007. 